Southeast Asian Journal of Islamic Education Management

Vol. 1 No. 1 (2020), pp 1-8

http://sajiem.iainponorogo.ac.id/sajiem
p-ISSN: 2716-0599

e-ISSN: $2715-9604$

\title{
STRATEGI KEPALA SEKOLAH DALAM MENINGKATKAN MANAJEMEN PELAYANAN KHUSUS MADRASAH (STUDI KASUS MADRASAH IBTIDAIYAH MA'ARIF LENGKONG SUKOREJO PONOROGO)
}

\author{
Muhammad Ghafar \\ IAIN Ponorogo, Indonesia \\ Email: ghafar@iainponorogo.ac.id \\ Pryla Rochmawati \\ IAIN Ponorogo, Indonesia \\ Email: pryla@iainponorogo.ac.id
}

\author{
Ahmadi \\ IAIN Ponorogo, Indonesia \\ Email: ahmadibardan@yahoo.com \\ Kharisul Wathoni \\ IAIN Ponorogo, Indonesia \\ Email: wathonikharisul@yahoo.com \\ Aris Nurbawani \\ IAIN Ponorogo, Indonesia \\ Email: arisnurbawani@gmail.com
}

DOI: https://doi.org/10.21154/sajiem.vili.4

\begin{tabular}{|l|l|l} 
Received: 24 Oktober 2019 & Revised: 17 Desember 2019 & Approved: 27 Desember 2019
\end{tabular}

\section{ABSTRAK}

Artikel ini ingin menganalisis tentang strategi kepala sekolah dalam meningkatkan manajemen pelayanan khusus madrasah, konteks penelitian yang mendasari penelitian ini ialah karena kualitas sekolah salah satunya ditentukan oleh peran dan kepemimpinan kepala sekolah, disamping karena ada kualitas guru dan manajemen organisasi yang baik yang menentukan sekolah berkualitas. Sekolah yang berkualitas diperlukan inovasi dalam manajemen pelayanan pendidikan. salah satu inovasi pelayanan pendidikan di MI Ma'arif Lengkong Sukorejo Ponorogo ialah adanya manajemen pelayanan khusus madrasah yaitu pelayanan khusus perpustakaan dan pelayanan khusus kesehatan di madrasah. Keberhasilan dari pelaksanaan manajemen pelayanan khusus ini salah satunya adalah adanya strategi kepala sekolah yang tepat sasaran. Metode penelitian menggunakan pendekatan penelitian kualitatif dengan jenis penelitian studi kasus, sedangkan teknik 
pengambilan data peneliti menggunakan teknik wawancara, observasi, dan dokumentasi. Selanjutnya analisis data peneliti menggunakan teknik analisis domain, analisis taksonomi, analisis komponen, dan analisis tema. Temuan penelitian ini pertama, strategi kepala sekolah dalam meningkatkan manajemen pelayanan khusus perpustkaan melalui membangun budaya literasi sejak dini ialah 1) efektifitas manajemen pengelolaan perpustakaan sekolah, 2) pembuatan pedoman dan peraturan perpustakaan sekolah, 3) pekan berkunjung perpustakaan sekolah untuk menarik minat pengunjung dan pembaca di perpustakaan, 4) hiburan mencerdaskan melalui lomba bercerita yang diadakan di akhir setelah ujian tengah semester maupun setelah ujian akhir semester. Kedua, strategi kepala sekolah dalam meningkatkan manajemen pelayanan khusus kesehatan melalui kelas sehat adalah sebagaimana berikut: 1) memasang poster menjaga kesehatan setiap kelas, 2) kerjasama dengan puskesmas untuk memberikan penyuluhan pendidikan kesehatan, 3) membentuk unit kesehatan sekolah sebagai pusat pelayanan pertama bagi siswa dan guru, 4) mengadakan lomba kesehatan dan kebersihan untuk membangun kesadaran dan motivasi dalam menjaga kesehatan.

Kata Kunci: strategi kepala sekolah, pelayanan khusus perpustakaan, dan manajemen pelayanan khusus kesehatan.

\section{PENDAHULUAN}

Kualitas sekolah salah satunya ditentukan oleh peran dan kepemimpinan kepala sekolah, disamping karena ada kualitas guru dan manajemen organisasi yang baik yang menentukan sekolah berkualitas. Terkait dengan pentingnya kepala sekolah juga diungkapkan dalam penelitian Berman dan Mc Laughlin dalam Rosnani Hashim ${ }^{1}$ tentang kepala sekolah sebagai salah satu keberhasilan sekolah. Melihat pentingnya peran kepala dalam manajemen pendidikan maka pemerintah membuat standar kompetensi yang harus dimiliki kepala sekolah melalui melalui Peraturan Menteri Pendidikan Nasional Nomor 13

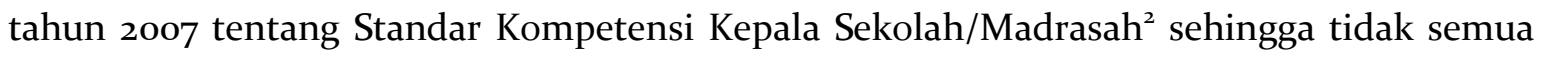
orang yang tidak memiliki kompetensi kepala sekolah bisa menjadi kepala sekolah, kepala sekolah harus memiliki standar kepala sebagaimana tercantum dalam Peraturan Menteri Pendidikan Nasional Nomor 13 tahun 2007 tentang Standar Kompetensi Kepala Sekolah/Madrasah.

Selanjutnya terkait dengan inovasi pelayanan madrasah akan menjadi nilai tambah bagi madrasah dalam memberikan pelayanan pendidikan kepada siswa dan masyarakat.

1 Rosnani Hashim. Educational Management from Islamic Perspective, dalam Proceeding International Annual Conference on Islamic Educational Management. Malang: UIN Maulana Malik Ibrahim Malang. 2012.

${ }^{2}$ Peraturan Menteri Pendidikan Nasional Nomor 13 tahun 2007 tentang Standar Kompetensi Kepala Sekolah/Madrasah 
Southeast Asian Journal of Islamic Education Management 1 (1) 2020)

manajemen pelayanan khusus diselenggarakan untuk kelancaran pelaksanaan belajar mengajar siswa juga untuk menarik siswa untuk memilih sekolah di madrasah. Keberhasilan dari pelaksanaan manajemen pelayanan khusus ini salah satunya adalah adanya peran kepala sekolah.

Pendidikan Madrasah Ibtidaiyah merupakan jenis pendidikan dasar dimana peserta didik masih berusia dibawah 12 tahun, sehingga membangun motivasi membaca literasi dan kesadaran akan kesehatan sejak usia dini juga diperlukan pendekatan dan startegi khusus, maka ketika sekolah mempunyai program manajemen pelayanan khusus peran kepala sekolah dalam melakukan strategi manajemen madrasah sangat penting untuk keberhasilannya.

Untuk melihat manajemen pelayanan pendidikan di MI Ma’arif Lengkong Sukorejo Ponorogo peneliti melakukan observasi ${ }^{3}$ pada pelayanan pendidikan, berdasarkan pengamatan peneliti diketahui bahwa ada pelayanan khusus yang menjadi program sekolah untuk meningkatkan proses belajar mengajar yaitu pelayanan khusus perpustakaan dan pelayanan khusus kesehatan sekolah. Melihat pentingnya motivasi membaca literasi siswa sejak dini serta pengetahuan kesehatan menjadikan pelayanan ini cukup menarik untuk diteliti tentang bagaimana pelaksanaan program pelayanan khusus tersebut dilaksanakan di madrasah.

\section{MEMBANGUN BUDAYA LITERASI SEJAK DINI: STRATEGI KEPALA SEKOLAH DALAM MENINGKATKAN MANAJEMEN PELAYANAN KHUSUS PERPUSTAKAAN MADRASAH}

Kompetensi kepala sekolah yang baik dapat dilihat dari perilaku kepemimpinannya melalui kepribadian kepala sekolah, pengetahuan dalam memimpin, merumuskan dan menjalankan visi dan misi sekolah, kemampuan mengambil keputusan, inovasi dalam membuat program sekolah, dan mampu berkomunikasi dengan baik. ${ }^{4}$

Strategi kepala sekolah dalam membangun budaya literasi sejak dini yaitu kepada para siswa madrasah ibtidaiyah merupakan langkah strategis ditengah masih minimnya motivasi membaca literasi bagi siswa. Pelaksanaan strategi tersebut oleh kepala sekolah diimplementasikan dalam sistem pelayanan khusus perpustakaan melalui sistem pelayanan terbuka hal ini sebagaimana hasil wawancara dengan kepala sekolah, dimana siswa dapat

\footnotetext{
${ }^{3}$ Hasil Observasi di MI Maarif Lengkong Sukorejo Ponorogo pada tanggal 13 Februari 2019

${ }^{4}$ Mulyasa, Menjadi Kepala Sekolah Profesional (Bandung: PT. Remaja Rosdakarya, 2004), 115.
} 
mencari, memilih, dan mengambil sendiri serta mencatat peminjaman buku secara mandiri di perpustakaan. Kondisi tersebut selaras dengan sistem pelayanan terbuka perpustakaan yang dikemukakan sumantri, dimana sistem pelayanan terbuka ialah memberikan kebebasan kepada peserta didik untuk mencari, melihat, dan mengambil sendiri buku yang ingin dipelajari. ${ }^{5}$

Meskipun siswa diberikan kebebasan dalam mengakses perpustakaan, kepala sekolah juga membuat kebijakan peraturan perpustakaan yang meliputi pedoman membaca di perpustakaan, pedoman peminjaman buku perpustakaan. Selanjutnya dalam peminjaman buku siswa dibatasi dengan dua buah buku pada waktu sekali peminjaman buku, namun ketika siswa sudah mengembalikan buku, maka diperbolehkan meminjam kembali dengan aturan peminjaman maksimal dua buku. Hal ini sebagaimana hasil wawancara dengan guru yang bertanggung jawab pengelola perpustakaan bahwa pembatasan tersebut agar siswa dapat membaca secara maksimal, serta siswa yang lain juga dapat membaca koleksi buku yang ada, karena koleksi buku jumlahnya masih terbatas.

Sebagai sekolah di desa, dengan berbagai kendala keterbatasan anggaran keuangan serta minimnya akses literasi perpustakaan daerah yang jaraknya jauh dengan sekolah dan domisili siswa. Kepala sekolah memiliki perhatian lebih dan mempunyai langkah strategis dalam membangun budaya literasi serta memenuhi sarana dan prasarana perpustakaan sekolah. Karena dengan terbangunnya budaya literasi, maka pengetahuan siswa akan semakin luas. Hal ini sebagaimana yang disampaikan kepala sekolah.

Kemampuan kepala sekolah dalam mengelola dan menyediakan kebutuhan sarana dan prasarana perpustakaan menjadi indikator kepala sekolah yang mempunyai kompetensi manajerial yang baik sesuai dengan Peraturan Menteri Pendidikan Nasional Nomor 13 tahun 2007 tentang Standar Kepala Sekolah ${ }^{6}$.

Keberadaan perpustakaan di MI Ma’arif Lengkong Sukorejo Ponorogo, sebagaimana hasil wawancara dengan kepala sekolah bukan hanya sebagai koleksi simpanan buku, namun perpustakaan sekolah dimanfaatkan untuk proses belajar mengajar, serta sumber belajar siswa sehingga pengadaan buku perpustakaan disesuaikan dengan kurikulum yang diterapkan di MI Ma’arif Lengkong Sukorejo Ponorogo agar buku yang dimiliki bisa menjadi

5 M. T. Sumantri, Panduan Penyelenggaraan Perpustakaan Sekolah (Bandung: PT Remaja Rosdakarya, 2008), 78.

6 Peraturan Menteri Pendidikan Nasional nomor 13 tahun 2007 tentang Standar Kepala Sekolah/Madrasah (Jakarta: Departemen Pendidikan Nasional, 2007). 
sumber belajar siswa. Terkait hal tersebut selaras dengan pendapatnya Ibrahim Bafadal, bahwa pengadaan buku perpustakaan sekolah hendaknya mempertimbangkan kurikulum sekolah, serta kondisi psikologis dan minat bacaan siswa?

Salah satu strategi kepala sekolah dalam membangun budaya membaca literasi siswa sebagaimana hasil wawancara serta observasi ialah dengan ada pekan berkunjung ke perpustakaan serta mengadakan perlombaan terkait dengan budaya membaca literasi seperti lomba mendongeng, hal ini telah mendorong siswa untuk berkunjung ke perpustakaan dan membaca buku. Pekan berkunjung dan perlombaan tersebut dilaksanakan diakhir setelah pelaksanaan ujian tengah semester maupun ujian akhir semester, jadi semacam hiburan yang mencerdaskan.

Berdasarkan uraian tersebut, dapat disimpulkan bahwa strategi kepala sekolah dalam meningkatkan manajemen pelayanan khusus perpustkaan melalui membangun budaya literasi sejak dini ialah 1) efektifitas manajemen pengelolaan perpustakaan sekolah, 2) pembuatan pedoman dan peraturan perpustakaan sekolah, 3) pekan berkunjung perpustakaan sekolah untuk menarik minat pengunjung dan pembaca di perpustakaan, 4) hiburan mencerdaskan melalui lomba bercerita yang diadakan di akhir setelah ujian tengah semester maupun setelah ujian akhir semester.

\section{KELAS SEHAT: STRATEGI KEPALA SEKOLAH DALAM MENINGKATKAN MANAJEMEN PELAYANAN KHUSUS KESEHATAN MADRASAH}

Pengetahuan kesehatan para siswa selama ini hanya diketahui ketika ada imunisasi di sekolah, selanjutnya petugas medis memberikan pendidikan kesehatan, sedangkan ketika di rumah tidak semua orang tua mengajarkan tentang bagaimana merawat dan menjaga kesehatan secara mandiri. Padahal kesehatan merupakan salah satu kebutuhan dasar setiap individu untuk mengetahui dan menjaga kesehatan dengan baik. Melihat problematika tersebut, sebagaimana hasil wawancara dengan kepala sekolah diketahui bahwa, kepala sekolah ingin madrasah menjadi tempat untuk mengetahui kesehatan. Secara lebih khusus kepala sekolah ingin membangun kesadaran kesehatan dari kelas siswa.

Berdasarkan hasil observasi dan wawancara dengan kepala sekolah serta dewan guru diketahui bahwa, tidak semua siswa Madrasah Ibtidaiyah (MI) Ma'arif Lengkong Sukorejo Ponorogo mempunyai pengetahuan tentang menjaga dan merawat kesehatan secara

\footnotetext{
${ }^{7}$ Ibrahim Bafadal, Pengelolaan Perpustakaan Sekolah (Jakarta: Bumi Aksara, 20o8), 5.
} 
mandiri, sehingga kepala sekolah dan para dewan guru mempunyai langkah strategis tentang kesadaran kesehatan yang dimulai dari kelas. Karena selama ini banyak siswa yang izin karena sakit, atau sakit gigi.

Strategi kepala sekolah tentang kesadaran kesehatan melalui program kelas sehat yaitu memasang poster tentang kesehatan di setiap kelas, mulai cara menggosok gigi, dan makan makanan yang sehat dan bergizi serta cara mencuci tangan dan makan-makanan yang akan dimakan. Serta ketika upacara sekolah, kepala sekolah memberikan arahan tentang menjaga kesehatan mulai dari diri sendiri dan manjaga kebersihan lingkungan. Hal ini sebagaimana diungkapkan salah satu dewan guru ${ }^{8}$.

Disamping hal tersebut, peneliti mengetahui bahwa ada kerjasama dengan puskesmas untuk memberikan penyuluhan pendidikan kesehatan kepada para siswa serta melakukan imunisasi kepada para siswa, disamping kegiatan tersebut kepala sekolah juga membuat pusat pelayanan kesehatan siswa melalui program Unit Kesehatan Sekolah (UKS). Peran UKS di madrasah sebagaimana pemaparan kepala sekolah disamping sebagai pelayanan kesehatan pertama siswa dan guru di madrasah juga sebagai pusat pendidikan kesehatan di madrasah. Dimana sebagai pelayanan kesehatan pertama siswa dan guru di madrasah, yaitu ketika terjadi kecelakaan pada saat belajar mengajar di sekolah dapat diberikan pertolongan pertama atau ketika sakit, siswa atau guru dapat dirawat sementara di UKS.

Selanjutnya untuk membangun kesadaran tentang menjaga kesehatan siswa, kepala sekolah mempunyai program lomba kesehatan dan kebersihan, dimana lomba kesehatan dan kebersihan ini dilaksanakan setiap akhir ujian akhir semester genap, pelaksanaan lomba ini diikuti oleh seluruh kelas mulai dari kelas 1 sampai kelas 6 mulai dari perlombaan kebersihan kelas, lalu lomba menggambar tentang menjaga kesehatan. Kegiatan tersebut telah membangun motivasi dan kesadaran siswa tentang pentingnya menjaga kesehatan, mulai dari diri sendiri dan makan-makanan yang bergizi.

Adapun strategi kepala sekolah dalam meningkatkan manajemen pelayanan khusus kesehatan melalui kelas sehat adalah sebagaimana berikut: 1) memasang poster menjaga kesehatan setiap kelas, 2) kerjasama dengan puskesmas untuk memberikan penyuluhan pendidikan kesehatan, 3) membentuk unit kesehatan sekolah sebagai pusat pelayanan

\footnotetext{
${ }^{8}$ Wawancara dengan bu Indah guru kelas MI Maarif Lengkong Sukorejo Ponorogo pada tanggal
} 14 Februari 2019 
pertama bagi siswa dan guru, 4) mengadakan lomba kesehatan dan kebersihan setiap tahun sekali untuk membangun kesadaran dan motivasi dalam menjaga kesehatan.

\section{PENUTUP}

Kesimpulan dari artikel penelitian ialah sebagaimana berikut: pertama, strategi kepala sekolah dalam meningkatkan manajemen pelayanan khusus Perpustkaan melalui membangun budaya literasi sejak dini ialah 1) efektifitas manajemen pengelolaan perpustakaan sekolah, 2) pembuatan pedoman dan peraturan perpustakaan sekolah, 3) pekan berkunjung perpustakaan sekolah untuk menarik minat pengunjung dan pembaca di perpustakaan, 4) hiburan mencerdaskan melalui lomba bercerita yang diadakan di akhir setelah ujian tengah semester maupun setelah ujian akhir semester. Kedua, strategi kepala sekolah dalam meningkatkan manajemen pelayanan khusus kesehatan melalui kelas sehat adalah sebagaimana berikut: 1) memasang poster menjaga kesehatan setiap kelas, 2) kerjasama dengan puskesmas untuk memberikan penyuluhan pendidikan kesehatan, 3) membentuk unit kesehatan sekolah sebagai pusat pelayanan pertama bagi siswa dan guru, 4) mengadakan lomba kesehatan dan kebersihan setiap tahun sekali untuk membangun kesadaran dan motivasi dalam menjaga kesehatan. 
Southeast Asian Journal of Islamic Education Management 1 (1) 2020)

\section{DAFTAR PUSTAKA}

Bafadal, Ibrahim. Pengelolaan Perpustakaan Sekolah (Jakarta: Bumi Aksara, 2008),

Hashim, Rosnani. Educational Management from Islamic Perspective, dalam Proceeding International Annual Conference on Islamic Educational Management. Malang: UIN Maulana Malik Ibrahim Malang. 2012.

Mulyasa, Menjadi Kepala Sekolah Profesional (Bandung: PT. Remaja Rosdakarya, 2004), 115.

Peraturan Menteri Pendidikan Nasional nomor 13 tahun 2007 tentang Standar Kepala Sekolah/Madrasah (Jakarta: Departemen Pendidikan Nasional, 2007).

Sumantri, M. T. Panduan Penyelenggaraan Perpustakaan Sekolah (Bandung: PT Remaja Rosdakarya, 2008)

Observasi di MI Maarif Lengkong Sukorejo Ponorogo pada tanggal 13 Februari 2019

Wawancara dengan bu Indah guru kelas MI Maarif Lengkong Sukorejo Ponorogo pada tanggal 14 Februari 2019 